\title{
Effect of Niobium Micro-Alloying Addition on Electrochemical Corrosion Behavior of Mild Steel in a Highly Alkaline Environment
}

\author{
Shulong Liu ${ }^{1}$, Chao Gao ${ }^{1, *}$, Ping Yan $^{2}$ \\ ${ }^{1}$ School of Physics and Electronic Information/Information College, Huaibei Normal University, \\ Huaibei, Anhui 235000, P R China \\ ${ }^{2}$ School of Life Science, Huaibei Normal University, Huaibei, Anhui 235000, P R China \\ *E-mail: gaochao@chnu.edu.cn
}

doi: $10.20964 / 2020.06 .42$

Received: 7 February 2020 / Accepted: 18 March 2020 / Published: 10 May 2020

\begin{abstract}
Corrosion behavior of niobium $(\mathrm{Nb})$ micro-alloyed steel in a highly alkaline environment were studied by electrochemical method. Electrochemical characterizations such as electrochemical impedance spectroscopy (EIS), potentiodynamic polarization and cyclic voltammetry (CV) were utilized to consider the $\mathrm{Nb}$ addition effect on corrosion resistance of mild steel. The current value decreased to zero potential with the increase of the $\mathrm{Nb}$ content in $\mathrm{CV}$ curves, which means that the addition of $\mathrm{Nb}$ facilitates the formation of stable passive film. The polarization results indicated that the mild steel with $0.03 \mathrm{wt} \% \mathrm{Nb}$ was in the passive region during the exposure time and had a smaller current than that of other samples. The EIS results indicated that the double-layer capacitance value reduced with the increase of $\mathrm{Nb}$ content which revealed that the passive film thickness had increased and resulted in the enhancement of the protective capacity when the $\mathrm{Nb}$ content of microalloyed steel was gradually increased. Scanning electron microscopy images indicated that the surface of the steel $(0.03 \mathrm{wt} \% \mathrm{Nb})$ was clean and smooth without any visible corrosion zones, which means that the sample had a suitable corrosion resistance even in an aggressive environment.
\end{abstract}

Keywords: Mild steel; Corrosion behavior; Electrochemical characterizations; Alkaline environment

\section{$\underline{\text { FULL TEXT }}$}

(C) 2020 The Authors. Published by ESG (www.electrochemsci.org). This article is an open access article distributed under the terms and conditions of the Creative Commons Attribution license (http://creativecommons.org/licenses/by/4.0/). 